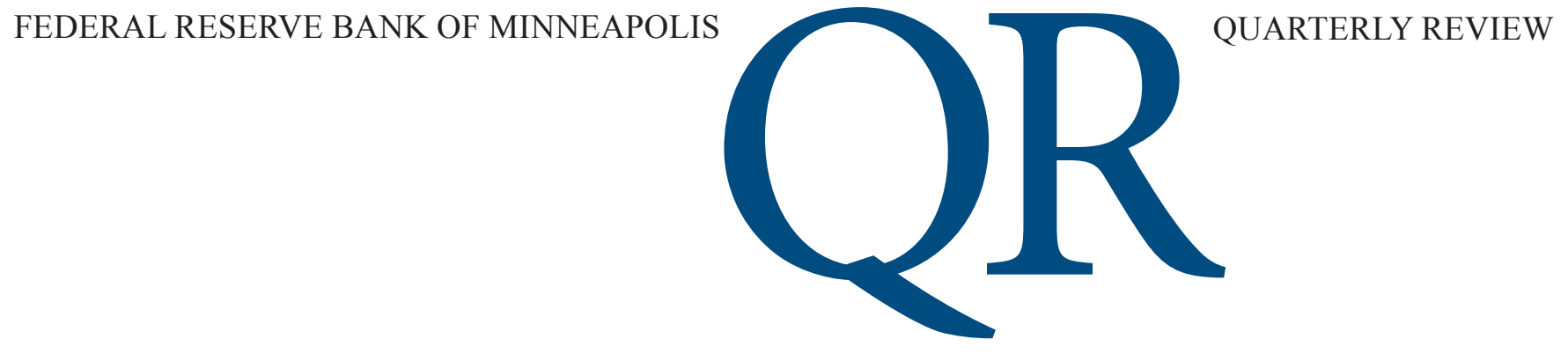

An Attractive Monetary Model with Surprising Implications for Optima: Two Examples

Neil Wallace 
FEDERAL RESERVE BANK OF MINNEAPOLIS

\section{Quarterly Review Vol.36, No.1}

\section{ISSN 0271-5287}

This publication primarily presents economic research aimed at improving policymaking by the Federal Reserve System and other governmental authorities.

The views expressed herein are those of the authors and not necessarily those of the Federal Reserve Bank of Minneapolis or the Federal Reserve System.

SENIOR VICE PRESIDENT AND DIRECTOR OF RESEARCH: Sam Schulhofer-Wohl

EDITOR: Kei-Mu Yi

ARTICLE EDITOR: Joan M. Gieseke

PRODUCTION EDITOR: Joan M. Gieseke

DESIGNER: Mark Shafer

TYPESETTING: Mary E. Anomalay

CIRCULATION ASSISTANT: Mary E. Anomalay

The Quarterly Review is published by the Research Department of the Federal Reserve Bank of Minneapolis. This has become an occasional publication; however, it continues to be known as the Quarterly Review for citation purposes. Subscriptions are available free of charge. To subscribe to the journal and be automatically notified whenever a new issue is published, please go to http://www.minneapolisfed.org/publications_papers/subscriptions/research/index.cfm to sign up. Readers will be notified by e-mail immediately upon publication.

Quarterly Review articles that are reprints or revisions of papers published elsewhere may not be reprinted without the written permission of the original publisher. All other Quarterly Review articles may be reprinted without charge. If you reprint an article, please fully credit the source - the Minneapolis Federal Reserve Bank as well as the Quarterly Review - and include with the reprint a version of the standard Federal Reserve disclaimer (italicized above). Also, please send one copy of any publication that includes a reprint to the Research Department of the Federal Reserve Bank of Minneapolis.

Electronic files of past Quarterly Review articles are available through the home page of the Federal Reserve Bank of Minneapolis, http://www.minneapolisfed.org.

Comments, questions, and subscription requests about the Quarterly Review may be sent to the circulation assistant at mary.anomalay@mpls.frb.org. 


\section{Contents}

An Attractive Monetary Model with Surprising Implications for Optima: Two Examples

Two examples of a monetary model-one about optimal inflation, the other about optimal seasonal policy - are used to study the consequences of monetary and fiscal policy. 


\title{
An Attractive Monetary Model with Surprising Implications for Optima: Two Examples*
}

\author{
Neil Wallace \\ Consultant \\ Research Department \\ Federal Reserve Bank of Minneapolis \\ and Professor of Economics \\ Pennsylvania State University
}

$\mathrm{T}$ he work of Ostroy (1973), Townsend (1989), and Kocherlakota (1998) helped initiate

the mechanism-design approach to monetary theory. The goal of that approach is to find settings in which money helps to achieve good outcomes - or, in Hahn's (1973) terminology, in which money is essential - and to use those settings to study the consequences of monetary and fiscal policy. Here, I present two examples that do that. The words attractive and surprising in the title are meant to challenge readers. Although I will offer my views about why the model is attractive at the end, readers must decide for themselves whether the model is attractive and whether the results are surprising.

One general conclusion that has emerged from the mechanism-design approach to monetary theory is that imperfect monitoring, some privacy of the history of individual actions, is necessary for essentiality of money (see Wallace 2010). (Stated casually, money is not needed in an isolated community in which everyone knows what each person has done in the past.) However, there are no general necessary and sufficient conditions for essentiality of money. Therefore, many monetary models rule out monitoring completely-either implicitly or explicitly — and make other extreme assumptions. ${ }^{1}$ Roughly speaking, the following conditions are sufficient for essentiality of money: no monitoring, discounting (that is not taken to the limit of no discounting), a large number of agents, some background absence of double coincidence, and no durable objects other than money. Although useful for some purposes, such economies have no credit and, somewhat less obviously, no taxation. Indeed, they are best viewed as extreme versions of underground economies. ${ }^{2}$ The absence of credit seems particularly troublesome for the study of monetary policy because the role of central banks is widely 
viewed to be intervention involving credit.

In order to get money and credit, there must be some monitoring - but not so much as to eliminate a role for money. About a dozen years ago, Ricardo Cavalcanti and I (see Cavalcanti and Wallace 1999) formulated such an intermediate situation by having some exogenous fraction of the population be perfectly monitored, labeled $m$-people, and having the rest, labeled $n$-people, be not monitored at all. The model was designed to compare inside money (i.e., private money) and outside money as alternative monetary systems. Here, I review some work by Alexei Deviatov and me that uses an outside-money version of that model to study optimal policy.

I describe optima for two arbitrary numerical examples: one about optimal inflation, the other about optimal seasonal policy. Despite the arbitrariness of those examples, they strongly hint at three general and related conclusions - general in the sense that they should hold for almost all models that give rise to a role for money. First, if the model is known, then intervention is optimal. Second, it is not easy to guess at even the qualitative nature of optimal intervention. Third, the optimum depends on the details of the model.

Those conclusions are reminiscent of second-best theory; if the first best is unattainablefor example, because some sector of the economy produces unavoidable externalities - then optimal policy can call for interventions throughout the economy, interventions that depend on a detailed description of the entire economy. Somewhat similar conclusions apply to optimal policy in any reasonably general model that gives rise to a role for money. In such a model, the features of a model that give rise to a role for money make the first best unattainable in the absence of intervention. As a consequence, some kind of intervention is desirable. However, even under optimal intervention, the first best is unattainable. Moreover, the nature of the beneficial intervention depends on the details of the economy and may not be consistent with simple general principles like the Friedman rule.

\section{The Environment}

The background setting is borrowed from Shi (1995) and Trejos and Wright (1995), a pure currency economy with pairwise meetings at random and with an absence-of-double-coincidence situation in every meeting. Time is discrete and there is a nonatomic measure of people, each of whom maximizes expected discounted utility with discount factor $\beta \in(0,1)$. Production and consumption occur in pairwise meetings that occur at random in the following way. Just prior to such meetings, each person looks forward to being a consumer (a buyer) who meets a random producer (a seller) with probability $1 / K$, looks forward to being a producer who meets a random consumer with probability $1 / K$, and looks forward to no pairwise meeting with probability $1-(2 / K)$, where integer $K \geq 2$. The period utility of someone who becomes a consumer and consumes $y \in \mathbb{R}_{+}$is $u(y)$, where $u$ is strictly increasing, strictly concave, and differentiable, and satisfies $u(0)=0$. The period utility of someone who becomes a producer and produces $y \in \mathbb{R}_{+}$ is $-c(y)$, where $c$ is strictly increasing, convex, and differentiable, and satisfies $c(0)=0$. In addition, $y^{*}=\arg \max _{y \geq 0}[u(y)-c(y)]$ exists and is positive. Production is perishable; it is either consumed or lost. ${ }^{3}$ In addition, either $u$ is bounded above or $c$ is such that $y$ is bounded above, an assumption that allows us to invoke the principle of one-shot deviations (see Figure 1). 


\section{Determinants of payoffs in a period}

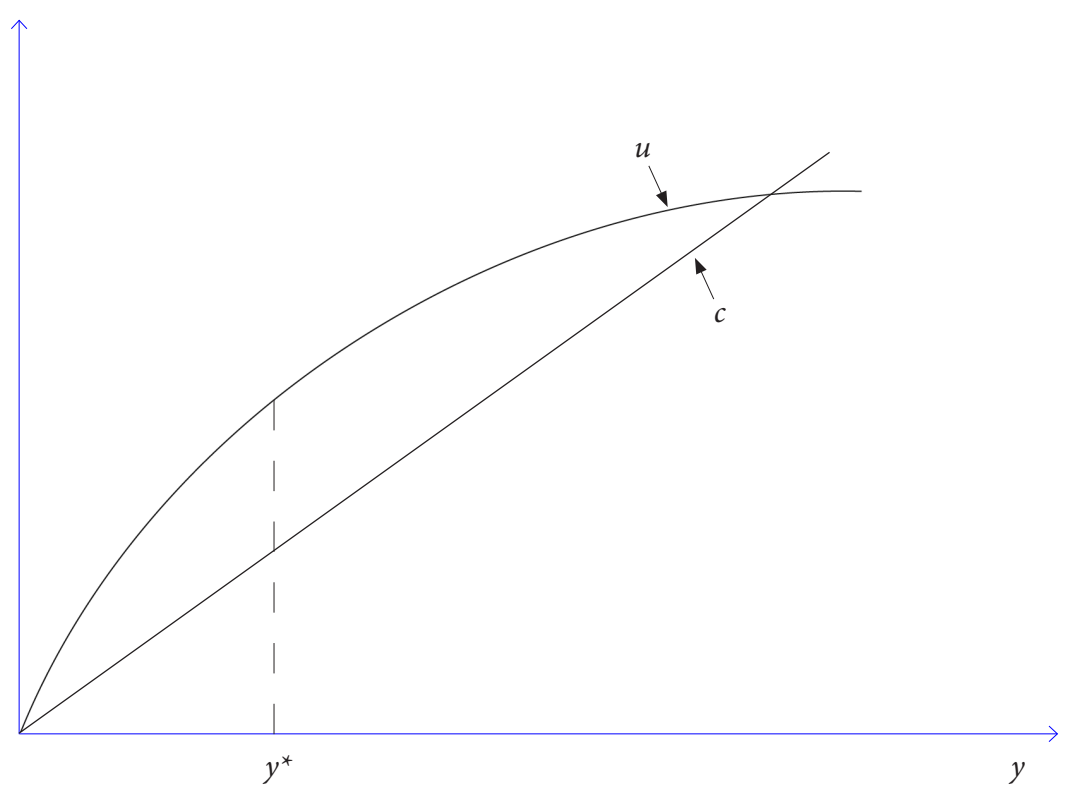

People in the model are ex ante identical, but the fraction $\alpha$ become permanently monitored ( $m$-people), whereas the rest are permanently nonmonitored ( $n$-people) ${ }^{4}$ For $m$-people, histories and money holdings are common knowledge; for $n$-people, they are private. However, the monitored status and consumer-producer status of people in a pairwise meeting are common knowledge. And no one except the mechanism designer, the planner, can commit to future actions.

At each date, there are two stages. The first stage has the pairwise meetings just described. At a second stage, transfers of money are made by the planner. Neither production nor consumption occurs at the second stage. Money is uniform and indivisible, and each person's holding of money is limited to be in the set $\{0,1\}$ at any time.

The only feasible punishment is permanent banishment of an individual $m$-person to the set of $n$-people. Underlying this assumption about punishment is free exit at any time from the set of $m$-people into the set of $n$-people and the ruling out of global punishments-like the shutting down of all trade in response to individual defections.

\section{Implementable Allocations and the Optimum Problem}

The search for an optimum is limited to allocations that are steady states and are symmetric, where symmetry means that all people in the same situation take the same action, an action that can be a lottery. (Lotteries take the form of some deterministic amount of output traded for a probability of getting money.) The state of the economy entering a date is $\left(\theta_{m}, \theta_{n}\right)$, where $\theta_{m} \in[0, \alpha]$ is the fraction who are $m$-people with money and $\theta_{n} \in[0,1-\alpha]$ is the fraction who are $n$-people with money. With $S=\{m, n\} \times\{0,1\}$, the state of a meeting is an 
element in $S \times S$, where the first component is the state of the producer and the second is that of the consumer. The planner chooses $\left(\theta_{m}, \theta_{n}\right)$, trades in meetings (as a function of the states of the producer and the consumer in the meeting), and second-stage transfers.

The planner is constrained by the steady-state restriction and by self-selection constraints that follow from the specification of private information and of punishments. The trades that the planner chooses for pairwise meetings are restricted to be individually rational (IR), immune to cooperative defection by the pair in any meeting, and incentive compatible (IC) for $n$ people. At the transfer stage, transfers are subject to being $I R$ and $I C$.

Several comments are in order about this notion of implementability. First, defection by an $n$-person has no further consequences for the person. Second, any defection by an $m$-person means permanent loss of $m$-status beginning at the next stage or date. The cooperative defection in meetings is static and ensures only that the trade is in the pairwise core for the meeting, taking as given the relevant continuation values. Third, as noted earlier, I am ruling out global punishments in response to individual defections. It may seem odd to have the planner choose trades in meetings - even subject to the requirement that there are no unexploited gains from trade. That is done for two reasons. First, there is no widely accepted theory about how those gains are divided. Second, I do not want conclusions about optimal intervention to depend on an arbitrary choice about how the gains from trade in meetings are divided.

The planner's objective is ex ante expected utility, where $\alpha$ is the probability of becoming an $m$-person and where the probabilities of starting with money are determined by $\left(\theta_{m}, \theta_{n}\right){ }^{5}$ This notion of welfare is easily shown to be proportional to the frequency-weighted average of the surpluses in meetings, namely,

$$
\sum_{s \in S} \sum_{s^{\prime} \in S} \pi_{s} \pi_{s^{\prime}}\left[u\left(y_{s s^{\prime}}\right)-c\left(y_{s s^{\prime}}\right)\right]
$$

where $y_{s s^{\prime}}$ is production and consumption when the producer is in state $s$ and the consumer is in state $s^{\prime}$ and where

$$
\left(\pi_{m 1}, \pi_{m 0}, \pi_{n 1}, \pi_{n 0}\right)=\left(\theta_{m}, \alpha-\theta_{m}, \theta_{n}, 1-\alpha-\theta_{n}\right)
$$

It follows that the first best is proportional to $u\left(y^{*}\right)-c\left(y^{*}\right)$ and has output equal to $y^{*}$ in every (single-coincidence) meeting. Later, welfare is expressed relative to that first-best welfare and output relative to $y^{*}$.

\section{Optimal Inflation}

In models with divisible money, a standard normalization holds the stock of money fixed and represents inflation by a proportional tax on money holdings. The approach taken here is the same, except that the discreteness of money in the model-each person's money holding is constrained to be in the set $\{0,1\}$ - dictates that we use a probabilistic version of such a tax: a person who ends up after trade with a unit of money loses it with some probability. This way 
of modeling inflation, which was first used by Li $(1994,1995)$ and has been used by others, has the same effects on incentives to acquire money as inflation in a model with divisible money. A literal interpretation is that money is made of stuff such that each unit disintegrates at each date with a probability that the planner chooses.

The following example is taken from Deviatov and Wallace (2012): $u(y)=1-e^{-10 y}$, $c(y)=y, K=3, \beta=.59, \alpha=1 / 4$. All the choices are arbitrary, except that for $\beta$. It is chosen to satisfy two conditions on optima for $\alpha \in\{0,1\}$, the extreme situations with regard to monitoring. First, given the other aspects of the specification, $\beta$ is such that if everyone is an $m$-person $(\alpha=1)$, then the first best is implementable. In other words, only the presence of $n$ people prevents implementability of the first best. Second, if everyone is an $n$-person $(\alpha=0)$, then it would be desirable to pay interest on money if doing so were feasible. Here are the details.

First consider $\alpha=1$. This is an economy with no role for money and one in which a defector is punished by permanent autarky (because the defector becomes the only $n$-person). In it, output $y$ in every single-coincidence meeting is implementable if and only if

$$
c(y) \leq \beta[u(y)-c(y)] / K(1-\beta),
$$

or, equivalently,

$$
c(y) \leq \beta u(y) /[\beta+K(1-\beta)] .
$$

(The left-hand side of (1) is the current utility cost of producing $y$, whereas the right-hand side is the benefit of not defecting.) Let $\bar{y}$ be the largest $y$ for which (2) holds at equality. Then any $y \in[0, \bar{y}]$ is implementable. The best implementable $y$ is $\min \left\{y^{*}, \bar{y}\right\}$. For our choice of $u, c$, and $K$, the smallest $\beta$ such that $\bar{y} \geq y^{*}$ is $\beta \approx .51$. Therefore, for our choice, $\beta=.59$, the optimum is the first best if $\alpha=1$.

Now consider $\alpha=0$. In this case, trade occurs only if the producer has no money and the consumer has money and optimal inflation is zero. (Given the bound on money holdings, an $n$-person with money cannot be induced to produce.) The relevant participation constraint is easily shown to be ${ }^{6}$

$$
c(y) \leq \beta u(y) /\left[\beta+K(1-\beta) /\left(1-\theta_{n}\right)\right] .
$$

Also, if $y=y^{*}$ and $\theta_{n}=1 / 2$ satisfy (3), then the optimum has $y=y^{*}, \theta_{n}=1 / 2$, and ex ante welfare equal to $1 / 4$ of the first best $-1 / 4$ because that is the fraction of single-coincidence meetings in which the producer has no money and the consumer has money when $\theta_{n}=1 / 2$. (Obviously, $\theta_{n}=1 / 2$ maximizes the fraction of single-coincidence meetings in which the producer has no money and the consumer has money.) If not, then the optimum has $y<y^{*}$, $\theta_{n}<1 / 2$, ex ante welfare less than $1 / 4$ of the first best, and payment of interest on money would be desirable (if it were feasible). For our choice of $u, c$, and $K$, the smallest $\beta$ for which (3) holds with $y=y^{*}$ and $\theta_{n}=1 / 2$ is $\beta \approx .67$. Thus, with $\beta=.59$ (the midpoint between $\beta=.51$ and $\beta=.67$ ), it would be desirable to pay interest on money because doing so would 
loosen constraint (3). ${ }^{7}$ Finally, notice that the best allocation when $\alpha=0$ is a feasible choice for the planner when $\alpha>0$.

With $\alpha=1 / 4$, the optimum has ex ante welfare equal to 34 percent of the first best, has $\theta_{m}=1 / 4$ (all $m$-people have money), has $\theta_{n}=.18$ (only about one-quarter of $n$-people have money), has a 16 percent inflation (disintegration) rate, and has no transfers to $n$-people at the second stage. These aspects of the optimum are best discussed after we see what happens in meetings. There are five (rather than eight) meetings in which trade can occur because an $n$-person with money cannot be induced to produce and because there are no $m$-people without money (see Table 1).

Table 1

Optimal trades

\begin{tabular}{cc}
\hline (Producer)(Consumer) & Output/(Money transferred) \\
\hline$(n 0)(n 1)^{*}$ & $0.573 /(1.0)$ \\
$(n 0)(m 1)^{*}$ & $0.573 /(1.0)$ \\
$(m 1)(n 0)$ & $0.113 /(0)$ \\
$(m 1)(n 1)^{*}$ & $0.381 /(1.0)$ \\
$(m 1)(m 1)^{*}$ & $0.381 /(\mathrm{n} / \mathrm{a})$ \\
\hline
\end{tabular}

*Denotes a binding producer $I R$ constraint.

In Table 1, an asterisk (*) means that there is a binding producer $I R$ constraint in the meeting. (In such meetings, all the gains from trade go to the consumer.) When the $n$-person without money is the producer (see rows 1 and 2), the trades are the same whether the consumer is an $n$-person or an $m$-person. The unit of money is transferred for output equal to about 57 percent of the first-best level. In rows 4 and 5, again all the gains from trade go to the consumer, but now the $I R$ constraint on the producer is tighter because defection by the producer would have a payoff equal to that of an $n$-person with money. ${ }^{8}$ Even though the row 3 trade does not have the $m$-person on the verge of defecting, a higher output in that meeting would decrease the discounted value of being in state $(m, 1)$ and increase that of being in state $(n, 0)$, and therefore would lead to a violation of the $I R$ constraints in all of the other meetings.

What does inflation accomplish? Because only about one-quarter of the $n$-people have money, the inflow of money into holdings by $n$-people (the row 2 meeting) is roughly three times the outflow (the row 4 meeting). Inflation reconciles those flows with a constant $\theta_{n}$, whereas transfers at the second stage reconcile those flows with a constant $\theta_{m}$. Here is one way to describe the transfers. The $m$-people could have a risk-sharing arrangement among themselves wherein those who end stage 1 with two units of money surrender one unit, with the proceeds distributed to those who end stage 1 without money. Given the stage 1 trades, 
transfers by the planner at each date are needed to reconcile those payments with a constant $\theta_{m}$. The inflows and outflows also help to account for why money is transferred in the row 4 meeting even though the $m$-person does not value the extra unit of money. (Indeed, production by $m$-people is due entirely to the threat of being banished to the set of $n$-people and can therefore be regarded as taxation.) If money was only displayed and not transferred in the row 4 meeting, then the net inflow into holdings of $n$-people implied by the trades would be even larger-which would necessitate other adjustments in trades or higher inflation (or both).

\section{Optimal Seasonal Policy}

Seasonal monetary policy was a major concern in the United States in the second half of the 19 th century and the early part of the 20th century. The dominant view at the time seemed to be that expressed by one of the stated goals of the Federal Reserve Act of 1913, the act that created the Federal Reserve System: "to furnish an elastic currency." That prescription seemed to mean that interest rates should be held constant in the face of a fluctuating seasonal demand for money. And the prescription seemed to be referred to approvingly in the following excerpt from a Financial Times article by Chris Giles, who quotes Mervyn King, then governor of the Bank of England. Describing a weather vane at the top of the Bank building, Giles writes:

[For the Bank of England in 1805,] knowing the direction of the wind was a deadly serious tool of monetary policy. ... If the wind was coming from the east, ships would soon be sailing up the Thames to unload goods in London. The Bank would need to supply lots of money, so traders could buy the wares landed at the docks. If a westerly was blowing, the Bank would mop up any excess money ... thereby avoiding inflation. ...

Distinguishing between demand for money and supply was easier in 1805 . When the wind blew from the east, and the ships sailed into London, Mr King said "the Bank of England knew that there was going to be a big demand shock for money" and it increased the notes and coins in circulation. ...

"If the Bank of England however had allowed money to increase without that demand shock occurring, when the ships weren't sailing up the river, then that would have generated inflation," [King] added. $^{9}$

It is easy to amend the previous model so that it contains a seasonal: have a two-date periodic $c$ function so that the disutility of production is higher at odd dates (winter) than at even dates (summer). ${ }^{10}$ In other respects, the model is the same except that inflation is not permitted (there is no possible disintegration of money). Now the task is to find the best two-date periodic implementable allocation (see Figure 2).

The example, which appears in Deviatov and Wallace (2009), has the first date be winter, $\alpha=1 / 4, K=3, u(y)=2 y^{1 / 2}, \beta=.95$, and

$$
c_{t}(y)=\left\{\begin{array}{ll}
y /(.8) & \text { if } t \text { is odd (winter) } \\
y /(1.25) & \text { if } t \text { is even (summer) }
\end{array}\right. \text {. }
$$

For this example, maximum surplus is attained at $y=.8$ in a winter meeting and at $y=1.25$ 


\section{Determinants of payoffs in each season}

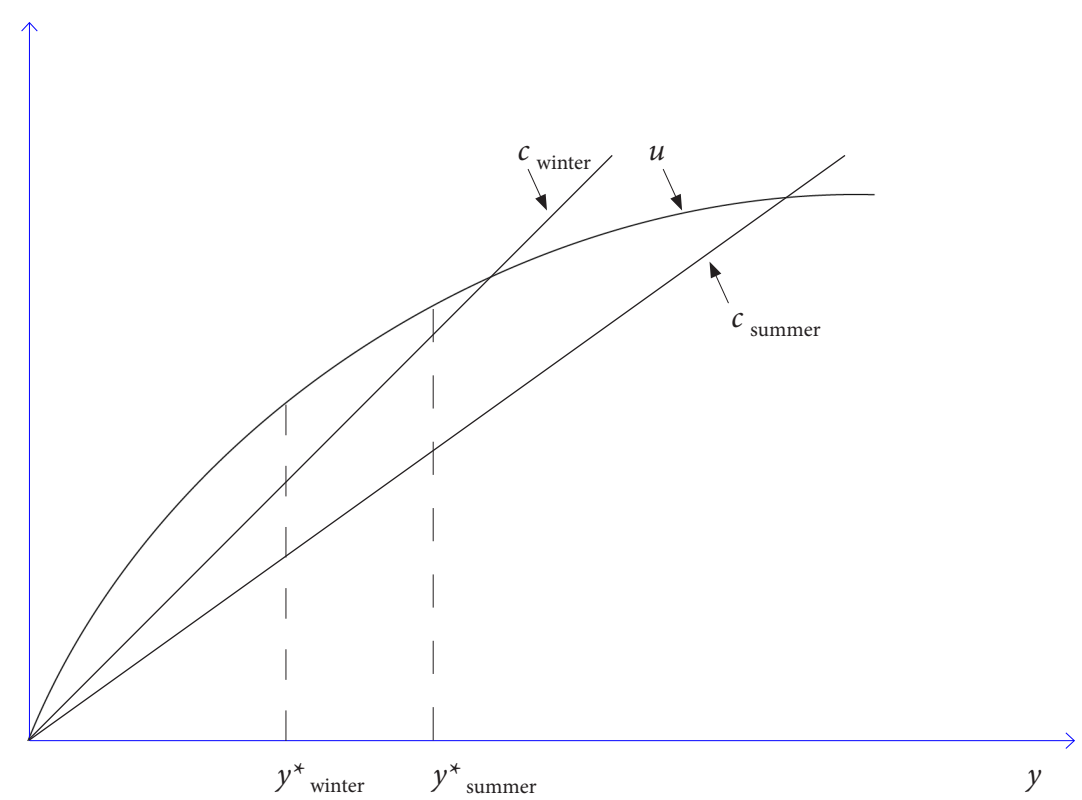

in a summer meeting. ${ }^{11}$ Also, first-best welfare is proportional to $[.8+\beta(1.25)]$. If everyone is monitored, then the first best is implementable; if no one is monitored, then the optimum is $\theta_{n}=1 / 2$ at every date, output is such that maximum surplus is attained when the consumer has money and the producer does not, and welfare is equal to $1 / 4$ of first-best welfare. With $\alpha=1 / 4$, the optimum is described in Tables 2 and 3 .

Again, all the $m$-people have money at the start of each date, and no transfers are made to $n$-people at the second stage of either date. Approximately two-fifths of the $n$-people start each date with money, but slightly more of them have money at the start of winter than at the start of summer. That being so, the stock of money is slightly larger at the start of winter than at the start of summer. The trades in meetings appear in Table 3.

As earlier, output at each date is expressed as a fraction of the respective first-best output, and the asterisk $\left(^{*}\right)$ denotes a binding producer $I R$ constraint. Now the dagger $(\dagger)$ denotes a binding truth-telling constraint (the $n$-person with money is indifferent between the row 4 trade and hiding money and getting the row 3 trade instead). When money transferred is in $(0,1)$, as in row 2 , it is the probability that the consumer transfers one unit to the producer.

In order to interpret optimal intervention, we again focus on inflows into and outflows from the money holdings of $n$-people. In winter, the difference is proportional to $(.750-.312)(.505)$ $-.312(.813)$, which is negative. And because there are no transfers to $n$-people at the second stage, those flows imply that fewer $n$-people have money at the start of summer than at the start of winter (see Table 2). In summer, an exactly offsetting net flow occurs - a consequence of the restriction to two-date periodic allocations without inflation. In order to reconcile those flows with every $m$-person starting with money at every date, $m$-people in the aggregate surrender 
An Attractive Monetary Model with Surprising Implications for Optima: Two Examples

Wallace

Table 2

Optimal quantity of money and welfare

\begin{tabular}{lcc}
\hline & Beginning of winter & Beginning of summer \\
\hline$\theta_{m}$ & $1 / 4$ & $1 / 4$ \\
$\theta_{n}$ & 0.312 & 0.309 \\
Welfare/First-best welfare & & .4558 \\
\hline
\end{tabular}

Table 3

Optimal trades in meetings

\begin{tabular}{lll}
\hline Meeting & \multicolumn{2}{c}{ Output/(Money transferred) } \\
\hline (Producer)(Consumer) & Winter & Summer \\
\hline$(n 0)(n 1)$ & $0.951 /(1.0)$ & $0.947 /(1.0)$ \\
$(n 0)(m 1)$ & $0.850^{*} /(.505)$ & $0.777^{\star} /(.776)$ \\
$(m 1)(n 0)$ & $0.161 /(0)$ & $0.171 /(0)$ \\
$(m 1)(n 1)$ & $1.177^{\dagger} /(.813)$ & $0.836^{\star \dagger} /(1.0)$ \\
$(m 1)(m 1)$ & $1.000 /(\mathrm{n} / \mathrm{a})$ & $0.836^{*} /(\mathrm{n} / \mathrm{a})$ \\
\hline
\end{tabular}

*Denotes a binding producer $I R$ constraint.

†Denotes a binding truth-telling constraint.

money at the beginning of summer and receive an exactly offsetting amount at the beginning of winter. Those transfers can be interpreted as zero-interest one-period loans extended by the planner to $m$-people at the beginning of winter with repayment at the beginning of summer. ${ }^{12}$

In this setting, no intervention would mean a total supply of money that does not vary with the season (see Deviatov and Wallace 2009 for a description of the best outcome subject to that constraint). It is no surprise that some intervention is beneficial: the optimum subject to a constant money supply is not first best, and intervention can have the money supply be higher at the start of winter than at the start of summer or vice versa. Because the nonintervention outcome is not first best, intervention in one of those directions will be beneficial for almost all parameters. Is having a higher money supply at the start of winter a general result? I doubt it. In Deviatov and Wallace (2009) that result shows up in all three examples, but those involve varying only $\alpha$, the fraction of people who are $m$-people. We did not study making summer the first date or varying other parameters of the model. ${ }^{13}$ 
An Attractive Monetary Model with Surprising Implications for Optima: Two Examples

Wallace

\section{Concluding Remarks}

The model has several attractive aspects: it is built up from fundamental ideas about the role of money; it has endogenous taxation and endogenous division of the gains from trade in meetings; and it was originally designed for a different purpose. It is special, however, in several respects.

People in the model meet in pairs to trade, and meetings occur at random. Regarding meetings in pairs, even if we set aside all of the descriptions of absence-of-double-coincidence situations that presume such meetings, there are good reasons for using such models. Pairwise meetings are, of course, one of the standard models in labor economics. In addition, they have been used to study the following diverse topics in monetary economics, none of which are easily addressed in models in which trade occurs among a large group. The topics include float (see Wallace and Zhu 2007), the denomination structure of currency (see Lee, Wallace, and Zhu 2005), the coexistence of money and higher return assets (see Zhu and Wallace 2007), and counterfeiting (see, for example, Hu 2013). Regarding the randomness of meetings, such randomness is simple and could, at a small cost in terms of additional structure, be replaced by heterogeneous taste shocks.

Another special assumption is money holdings in $\{0,1\}$. Such holdings do prejudice the result toward inflation in the first example. If $n$-people were to spend more than they earn in meetings with $m$-people, then money would have to be returned to $n$-people as transfers. With holdings in $\{0,1\}$, the transfers would have to go to those who would otherwise have no money. Such transfers have obvious harmful incentive effects on $n$-people who are producers in meetings. If, instead, money holdings were richer, say, $\{0,1,2, \ldots, B\}$ with $B$ large, then such transfers could be paid in a way that approximates payment of interest on money held by $n$-people. Nevertheless, I am skeptical that an optimum in such a version would resemble the Friedman rule. Spending by $m$-people serves several purposes in the model. Therefore, taxing them by having them earn more than they spend in meetings with $n$-people is costly. ${ }^{14}$

The assumption that an exogenous fraction of people are perfectly monitored is a special case of a model with a smooth distribution of costs of getting monitored across the population. In such a model, the planner chooses a cutoff cost subject to people self-selecting in accord with that cutoff. Some examples with such specifications are explored in Deviatov and Wallace (2012), who find that the extreme version used earlier is not misleading. More interesting and challenging is a departure from the extreme situation of some perfectly monitored people and others not monitored at all. Some preliminary work on a model of that sort is in Mills (2008).

One possible concern about the model studied here is that optima are difficult to describe. That difficulty is due to a general feature of the model. The examples are such that the optima at both extremes - either all $m$-people or all $n$-people - are easy to describe because neither has an endogenous state variable. Therefore, each is a simple repeated game. ${ }^{15}$ In contrast, versions with both types have an endogenous state variable, namely, the distribution of money holdings between the two types. As a consequence, the trades at a date play two distinct roles: they affect the current payoff (current trades), and they help to determine the distribution at the next date, which matters for future payoffs (future trades). That multiple role for trades, 
An Attractive Monetary Model with Surprising Implications for Optima: Two Examples

Wallace

which is not special to models with pairwise trades, and the impossibility of attaining the first best account for why the optimum is difficult to describe. ${ }^{16}$ Indeed, that difficulty is the message. Even though the examples are very simple - you can, as it were, hold either in one hand - it is not easy to guess at their implications for optima.

\section{Notes}

*An earlier and somewhat different version of this paper, entitled "An Alternative to New Keynesian Models for the Analysis of Optimal (Monetary) Policy," was prepared for presentation at the conference "Monetary Policy in the Presence of Micro-founded Market Frictions," Bank of Italy, Rome, June 6-7, 2013. I am indebted to Randy Wright for helpful comments on an earlier version.

${ }^{1}$ Whenever borrowing and lending is ruled out—as, for example, in Lucas (1980), Bewley (1983), and many other papers - the implicit assumption is no monitoring.

${ }^{2}$ See Wallace (2014) for a discussion of optimal policy in such economies.

${ }^{3}$ If $K$ exceeds 2, then, as is well known, it can be interpreted as the number of goods and specialization types, as in Shi (1995) and Trejos and Wright (1995).

${ }^{4}$ The interpretation is that the fraction $\alpha$ realize a zero cost of attaining $m$-status and that the rest realize a prohibitively high cost of attaining $m$-status. We will see that $m$-people want to become monitored.

${ }^{5}$ One could also study Pareto allocations by distinguishing between people by monitored status or by monitored status and initial money holdings.

${ }^{6}$ In order to derive this expression, start with $c(y) \leq \beta v(1)$, where $v(i)$ for $i \in\{0,1\}$ is the discounted value of starting a date with $i$ amount of money. Then, solve for $v(1)$ in terms of $y$ from the relevant linear equations in $v(0)$ and $v(1)$.

${ }^{7}$ The desirability of paying interest on money should be interpreted as follows. Consider two side-by-side economies that are identical except in one respect. In one the money is barren; in the other, the money throws off a real dividend at each date - a so-called Lucas tree. Welfare in the tree economy is higher by more than the additional utility of consumption implied by the dividend. Some would say that the tree has liquidity value, others (see Harrison and Kreps 1978) would say it has speculative value.

${ }^{8}$ See Deviatov and Wallace (2014) for the comparable and better outcome using inside money.

${ }^{9}$ Chris Giles, "Winds of Change," Financial Times, May 14, 2007.

${ }^{10}$ As is well known, Minneapolis has only two seasons: winter and road repair.

${ }^{11}$ Although this example does not satisfy the boundedness requirement, it is easily amended to satisfy it in a way that does not affect the optimum. One possibility is to assume that (4) holds only for $y \leq \bar{y}$ and that $c(y)=\infty$ for $y \geq \bar{y}$, where $\bar{y}$ is sufficiently large - say, 100 .

${ }^{12}$ See Cavalcanti and Nosal (2009) for a similar background setting, but with only $n$-people. They permit random confiscation of money held by $n$-people, which is not allowed according to the notion of implementability used here. Whether their class of policies could, instead, be described as positive transfers and inflation is not immediately apparent.

${ }^{13}$ Of course, real business cycle enthusiasts will notice that the seasonal example is a special case of a real business cycle model. Nothing in principle prevents changing the model into one with a random process for the disutility of production. Such a model with only $n$-people is studied in Cavalcanti and Erosa (2008) and in Huang and Igarashi (2012).

${ }^{14} \mathrm{~A}$ similar effect on welfare appears in Antinolfi, Azariadis, and Bullard (forthcoming). They have a two-sector model in which $m$-people interact solely with each other in a Kehoe-Levine (1993) credit market, whereas $n$-people interact solely with each other in a market with spot trade in money. As in our model, $m$-people face the threat of being banished to the set of $n$-people. In other respects, the models are very different. In our model, as highlighted earlier, the in-equilibrium interactions between $m$-people and $n$-people are central to the results.

${ }^{15}$ The version with only $n$-people is a repeated game because with money holdings in $\{0,1\}$, the fraction who end the first stage with money is unaffected by the first-stage trades. 
An Attractive Monetary Model with Surprising Implications for Optima: Two Examples

Wallace

\begin{abstract}
${ }^{16}$ There are well-known and widely used devices for eliminating that multiple role of trades. One is the so-called large family (for a recent example, see Gertler and Kiyotaki 2010). Another is periodic centralized trade with quasi-linear preferences (see Lagos and Wright 2005 and its many offshoots). But is it desirable to make such assumptions? If we conclude, as I believe we should, that the above multiple role of trades and the impossibility of attaining the first best are general features of models of monetary economies, then we should live with those features and with the difficulty of describing their implications.
\end{abstract}

\title{
References
}

Antinolfi, Gaetano, Costas Azariadis, and James Bullard. Forthcoming. "The Optimal Inflation Target in an Economy with Limited Enforcement." Macroeconomic Dynamics.

Bewley, Truman. 1983. “A Difficulty with the Optimum Quantity of Money.” Econometrica 51 (5): 1485-1504.

Cavalcanti, Ricardo de O., and Andrés Erosa. 2008. "Efficient Propagation of Shocks and the Optimal Return on Money." Journal of Economic Theory 142 (1): 128-48.

Cavalcanti, Ricardo de O., and Ed Nosal. 2009. "Some Benefits of Cyclical Monetary Policy.” Economic Theory 39 (2): 195-216.

Cavalcanti, Ricardo de O., and Neil Wallace. 1999. "Inside and Outside Money as Alternative Media of Exchange." Journal of Money, Credit and Banking 31 (3, pt. 2): 443-57.

Deviatov, Alexei, and Neil Wallace. 2009. "A Model in Which Monetary Policy Is about Money." Journal of Monetary Economics 56 (3): 283-88.

_. 2012. "Interest on Cash with Endogenous Fiscal Policy." Unpublished.

- 2014. "Optimal Inflation in a Model of Inside Money." Review of Economic Dynamics 17 (2): 287-93.

Gertler, Mark, and Nobuhiro Kiyotaki. 2010. "Financial Intermediation and Credit Policy in Business Cycle Analysis." In Handbook of Monetary Economics, vol. 3A, edited by Benjamin A. Friedman and Michael Woodford, 547-600. Amsterdam: North-Holland.

Hahn, Frank H. 1973. "The Foundations of Monetary Theory." In Essays in Modern Economics: The Proceedings of the Association of University Teachers of Economics, Aberystwyth 1972, edited by Michael Parkin and A. R. Nobay, 21-43. New York: Barnes and Noble.

Harrison, J. Michael, and David M. Kreps. 1978. "Speculative Investor Behavior in a Stock Market with Heterogeneous Expectations." Quarterly Journal of Economics 92 (2): 323-36.

Hu, Tai-Wei. 2013. "Imperfect Recognizability and Coexistence of Money and Higher-Return Assets.” Economic Theory 53 (1): 111-38.

Huang, Pidong, and Yoske Igarashi. 2012. "A Comment on: 'Efficient Propagation of Shocks and the Optimal Return on Money." Journal of Economic Theory 147 (1): 382-88.

Kehoe, Timothy J., and David K. Levine. 1993. "Debt-Constrained Asset Markets.” Review of Economic Studies 60 (4): $865-88$.

Kocherlakota, Narayana R. 1998. “Money Is Memory.” Journal of Economic Theory 81 (2): 232-51.

Lagos, Ricardo, and Randall Wright. 2005. "A Unified Framework for Monetary Theory and Policy Analysis.” Journal of Political Economy 113 (3): 463-84.

Lee, Manjong, Neil Wallace, and Tao Zhu. 2005. "Modeling Denomination Structures.” Econometrica 73 (3): 949-60.

Li, Victor E. 1994. "Inventory Accumulation in a Search-Based Monetary Economy.” Journal of Monetary Economics 34 (3): $511-36$.

1995. "The Optimal Taxation of Fiat Money in Search Equilibrium." International Economic Review 36 (4): 927-42. 
An Attractive Monetary Model with Surprising Implications for Optima: Two Examples

Wallace

Lucas, Robert E., Jr. 1980. “Equilibrium in a Pure Currency Economy.” Economic Inquiry 18 (2): 203-20.

Mills, David C., Jr. 2008. “Imperfect Monitoring and the Discounting of Inside Money.” International Economic Review 49 (3): $737-54$.

Ostroy, Joseph M. 1973. “The Informational Efficiency of Monetary Exchange.” American Economic Review 63 (4): 597-610.

Shi, Shouyong. 1995. "Money and Prices: A Model of Search and Bargaining." Journal of Economic Theory 67 (2): 467-96.

Townsend, Robert M. 1989. “Currency and Credit in a Private Information Economy.” Journal of Political Economy 97 (6): 1323-44.

Trejos, Alberto, and Randall Wright. 1995. "Search, Bargaining, Money and Prices.” Journal of Political Economy 103 (1): $118-41$.

Wallace, Neil. 2010. "The Mechanism-Design Approach to Monetary Theory.” In Handbook of Monetary Economics, vol. 3A, edited by Benjamin M. Friedman and Michael Woodford, 4-24. Amsterdam: North-Holland.

. 2014. “Optimal Money Creation in 'Pure Currency' Economies: A Conjecture.” Quarterly Journal of Economics 129 (1): 259-74.

Wallace, Neil, and Tao Zhu. 2007. "Float on a Note." Journal of Monetary Economics 54 (2): 229-46.

Zhu, Tao, and Neil Wallace. 2007. "Pairwise Trade and Coexistence of Money and Higher-Return Assets.” Journal of Economic Theory 133 (1): 524-35. 